addition to their use for temporarily replacing. blood lost, are of great value in treating the toxaemic states-uraemia, eclampsia, etc.-the patient being bled and then infused; though here again a better result is obtained by using blood.

\section{Intravenous Medication.}

With regard to the introduction of remedies into the circulation I will confine my remarks to those of which I have personal experience.

Intravenous proteins I have used in the treatment of many disabilities-chiefly spasmodic asthma, infective arthritis, and chronic skin diseases, all conditions in which the nature of the infective agent has not been determined. I should say that about half the cases so treated have been benefited. The proteins used have been T.A.B emulsion 100 to 500 million, Bacillus coli emulsion 100 million, Staphylococcus aureus 500 million, and Witte's peptone, $10 \mathrm{c.cm}$. of a 2 per cent. solution. The most marked reaction is ushered in by a shivering attack, followed by a rapid rise of temperature, with a corresponding increase in the pulse rate; the leucocyte count is raised; headache, malaise, and aches and pains in joints and limbs may be present. The reaction passes in the course of thirty-six hours, and is followed in a favourable case by improvement in the clinical condition. The injections should be repeated four times or so at intervals of seven to ten days. There appears to be a direct relation between the amount of reaction and the improvement obtained; for this reason T.A.B. injection proves the most efficacious. Vaccines when given intravenously act more potently than when given under the skin. I believe that too much has been made hitherto of the specific nature of a vaccine, and that careful preparation is more important than any other single factor.

With regard to intravenous injection of antitoxic serums I have had a very limited experience. Candidly I am rather afraid of this method. I tried it during the war in cases of acute sepsis. I was never sure that the benefit obtained was commensurate with the reaction and upset to which it generally gave rise, and I am still not convinced that intravenous serum has any advantages over the intramuscular and subcutaneous routes.

Of the other remedies I have used intravenously I may mention in particular mercury perchloride. So high an opinion have I formed of this drug that I think every clinician who may be called upon to treat acute cases should keep a solution of it prepared; a suitable dose$1 / 64,1 / 32$, or $1 / 16$ grain-could then readily be chosen; the strength I suggest is 1/16 grain of mercury perchloride in $8 \mathrm{ccm}$. of normal saline. I have used it chiefly in the following conditions: (1) pneumonia, lobar and lobular; (2) acute staphylococcal infections; (3) chorea; subacute rheumatism; (4) chronic infective arthritis of undetermined origin; (5) encephalitis lethargica.

The treatment of lobar pneumonia has hitherto chiefly been symptomatic. I have from time to time tried various serums, and also typed vaccine, but have not been struck by the results. Quite empirically I started, about eighteen months ago, systematically injecting cases of lobar pneumonia, at whatever stage they came under observation, with 1/32 grain of mercury perchloride. Most of those I have so far treated have responded favourably. Such figures as I have point to an association between the injaction of the mercury perchloride and the favourable turn which these cases have taken. I have had quite marked results in bronchopneumonia also, especially in children. Infections by Staphylococcus aureus appear to be consistently benefited by injections of perchloride. It is of value in the more chronic infections, such as boils, and in the acute cases, such as acute infective osteomyelitis.

It is a matter of common experience that acute rheumatisin under treatment usually clears up within a short time, but the subacute forms, particularly in children, with possible endocarditis and manifestations of chorea, hang fire; the treatment of these patients is unsatisfactory. I have injected a number of these cases with mercury perchloride. Some cases of chorea I have treated have shown improvement in the movements and in the general health, but the fever has continued; in the end the fever too has disappeared. I realize that here, as with pneumonia, one is on very shifty ground, for these things may happen by treating with rest alone. It is only, however, by taking a large number of cases treated with mercury, and comparing them with a similar number treated without, that it is possible to arrive at conclusions. My impressicn, so far, is distinctly favourable to the mercury treatment.

Cases of chronic infective arthritis, where there is no septio focus which can be determined after careful search, have been improved by intravenous injections of mercury perchloride 1/32 grain every three days. I have also used in such cases sodium salicylate 15 grains with sodium iedide 15 grains in $20 \mathrm{c.cm}$. of distilled water.

Among many other drugs which have been used intravenously iron cacodylate in half-grain doses every other day is a very efficient way of raising the haemoglobin content. Tylcalcin (a calcium salt of salicylic acid) is a useful form of salicylate for intravenous injection in acute and subacute rheumatism. Acriflavine $(40 \mathrm{c.cm}$. of 1 in 1.000 solution in normal saline) should certainly be tried in septicaemia. Magnesium sulphate $(20$ c.cm. of a 10 per cent. solution) is of use in controlling the convulsions in eclampsia and uraemia by virtue of its sedative action on voluntary muscle; it also promotes urinary secretion when given intravenously. Urotropine acts more powerfully when given intravenously.

How do these intravenous remedies act? On this point I must at once confess ignorance. It is inconceivable that 1/32 grain of mercury perchloride, for exarnple, can have any antiseptio action when diluted in the blood stream. Perhaps the reaction may be simply that which is assiciated with putting a foreign substance in the blood stream.

The intravenous route has much to recommend it. By whatever channel drugs are given, they must ultimately reach the circulating blood. Therefore it would appear to be only logical to put them straight into the blood stream. But intravenous medication demands careful handling, and, in using it, one must err on the side of caution.

\section{THE TREATMENT OF RODENT ULCER BY TRICHLORACETIC ACID.}

BY

\section{H. LESLIE-ROBERTS, M.D.,}

LATELY LECTURER IN DISEASES OF THE SKIN IN THE UNIVERSITY ON LIVERPOOL; CONSULTING DERMATOLOGIST TO THE LIVERPOOL ROYAL INFIRMARY.

BFrone the days of radium and $x$ rays surgeons were often compelled to treat malignant growth by means of caustics. The need of some chemical which would destroy the growth was felt when the growth occurred on the eyelids or the inner canthus of the eyes, or on the side of the nose; or in the nostril, where complete removal of the growth would entail great deformity.

Various caustics were employed, such as solid "potassa fusa," zino chloride, acid nitrate of mercury, Vienna or arsenical paste, antimony, and pyrogallic acid. The use of these chemical agents gradually dropped into oblivion, since their use was accompanied, not only by severe pain, but not infrequently by accelerated metabolism, wherelby a quiet growing tumour was converted into a growth of a more malignant type.

We know why these caustics fell into disrepute; it was because of their dangerous tendency to set up oedema, which was followed by rapid destruction of cells in the superficial parts of the tumours with absorption of toxio products and accelerated growth in the deeper parts. It may be laid down as a general rule that a caustic which increases the water contents of a malignant cell should always be avoided.

The superiority of trichloracetio acid in the treatment of rodent ulcer lies in the fact that its action leads to complete coagulation of the cell contents. The compounds 
fcrmed between the acid and the cell oontents are nonhydrophil, and therefore do not tend to draw lymph out of the capillaries. In consequence of this property the acid converts the neoplasm into a solid block of dead tissue, which is gradually thrust out by the undergrowth of the healthy living cell of the epidermis. I need not enter here into the biochemical relations of this acid.*

Briefly stated, there are three chloracetic acids, according to the number of hydrogen atoms in the acetic acid molecule replaced by chlorine. The trichloracetic acid possesses in highest measure the characters of the group. Among the most remarkable of these properties is the power of dissolving both water, and oils and fats; trichloracetic acid is both hydrophil and oleophil. Its capacity for dissolving all the simple proteins is shown by its solvent action on solid tissues; skin, the various organs of the body, dead meat, and vegetable matter are reduced in time to a thin almost invisible membrane of connective tissues. Keratin itself is insoluble. Owing to its very powerful oleophil properties, trichloracetic acid is able to penetrate through living tissue. The time taken to penetrate varies in different regions of the body surface. Furthermore, the severity and duration of the reactions of the cutaneous tissues vary with the region occupied by those tissues. The skin covering the sides of the fingers and toes may be described as non-reactive, any. reaction that may appear being ephemeral. The acid penetrates rapidly through the normal flexor surfaces of the limbs, and the reactions slowly evolve in the course of many weeks. Penetration through the extensor surfaces is slower, and the reactions are of shorter duration.

Trichloracetic acid finds its highest utility in the treatment of rodent ulcer and all the benign forms of epithelial neoplasms-for example, milium tricho-epithelionata, fibrosebaceous moles, and hairy pigmented moles. Rosacea, which may be regarded as a seborrhoeic epithelial neoplastic disease, will yield to a 20 per cent. solution of this acid, which, however, is inferior to sulphur and salicylic acid in the treatment of the disease. Corns and warts yield more slowly, since penetration is difficult, but trichloracetic acid is probably our best remedy for these common benign neoplasms, the only safe alternative being electrolysis.

\section{Method of Application in Rodent Ulcer and Benign Epithelial Grouths.}

Trichloracetic acid is a crystalline substance which dissolves very readily in water. Three drachms of the acid require from 19 to 20 minims of water to form a concentrated liquid acid holding a small quantity of water in solution. A solid crystal should never be applied, for the sudden melting may result in extension of the acid far beyond the area intended. For safety's sake the adjacent skin should be protected by a smear of vaseline, but this is not always necessary. The applicator should be a glass rod, 1 to $2 \mathrm{~mm}$. in diameter according to the size of the area to be covered. Cotton-wool need not be used. The acid should be applied until the skin is definitely white over the whole area, and this should not exceed three-quarters of an inch. Penetration is accompanied by a smart stinging sensation. When penetration is effected the part is well bathed with water till all the stinging has ceased. In rodent ulcer and solid growths I generally allow three minutes before neutralizing with water. Usually from this time not the slightest discomfort is experienced by the patient; very occasionally a burning sensation has persisted for some hours. For the next twenty-four hours no soap or water should be allowed to come in contact with the treated skin. The dead tissue is to be allowed to separate spontaneously. The time taken for separation of the dry eschar is about twenty-two days. No ointments should be applied. After separation of the primary eschar a minute secondary crust sometimes forms and separates in the course of a few days-usually after four weeks from the application.

*A reader Interested in the subject will find a fuller account of these relations In the British Journal of Dermatology and Syphilis, August, September, and October, 1926.

\section{A HAEMOSTATIC CLAMP AS AN AID IN DISSECTION OF TONSILS.}

\author{
BY
}

L. GRAHAM BROWN, M.D., F.R.C.S.,

ASSISTANT SURGEON, EAR, NOSE, AND THROAT DEPARTMENT, CHARING CROSS hOSPITAL.

The method to be described is the application to tonsillectomy of the principle adopted in the surgery of other regions of the haemostatic clamping of an organ before incision.

The instrument I have designed for this purpose is made in pairs, a right and left, for adaptation to either tonsil. It has curved, flattened blades, which fit closely over the pillars of the fauces, and are covered by rubber sheaths to avoid injury to these soft tissues. The handles close the blades gently, though firmly, by means of a graduated ratchet, and are bent sharply downwards almost to a right angle in order not to obscure the view of the surgeon during his manipulations.

The Boyle-Davis gag is used, and the patient is in the usual dorsal pasition, with the head extended well backwards over a rounded sandbag. The operator sits at the head of the table, and employs any of the usual methods of illumination.

The application of the instrument is easy, and is well illustrated by the accompanying figure. The chief points to observe are: the lower blade is carefully manceuvred underneath the soft palate and deep to the posterior pillar; the upper blade is then brought into position upon the anterior pillar and its extension to the side of the tongue; the tonsil is next gripped with a pair of tenaculum forceps and pulled through the blades of the clamp until the latter are in the correct position for closure. The sliding action of the upper on the lower blade of the clamp as it closes itself helps in this protrusion of the tonsil from its bed, and hence the operator is chiefly concerned with the accurate adjust-

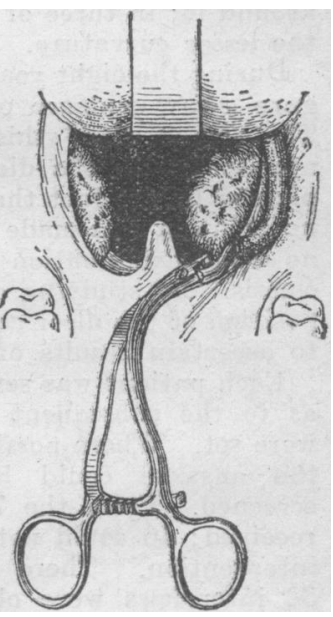

The clamp applied to right ment of the blades to the pillars, taking care that they are applied as far backwards from the free margins of the pillars as space will allow. All hold on the instrument can now be dispensed with and the actual dissection of the tonsil begun.

The following claims are made for the use of this haemostatic clamp:

1. The instrument can be applied in almost all cases, the comparatively few failures depending, not on the size or nature of the tonsil to be removed, but on the width of the pillars of the fauces.

2. During removal of the tonsil there is practically no bleeding.

3. The actual dissection is rendered quick, east, and complete, owing to the absence of haemorrhage and the fact that the tissue between the tonsil and its bed is squeezed into a thin line between the closed blades from which the tonsil readily separates.

4. No bruising of the soft tissues need occur.

5. The method is specially applicable in the case of small, fibrous, or adherent tonsils, and causes a minimum of destruction to the tissues of the pillars and tonsillar bed.

6 . The main vessels of supply to the tonsil can usually be readily seen during the dissection, picked up, and ligated if necessary.

7. The after-effects of operation are no greater than those of any other method of dissection.

8. Deep anaesthesia is not such an important factor to the surgeon as when dissection is carried out without the aid of the clamp.

9. With a smaller sized instrument children can be similarly operated upon in place of the guillotine method.

The instrument can be seen at Messrs. Allen and Hanburys (48, Wigmore Street, W.1), and is supplied by them. 